\title{
Article \\ Effect of Fibers on Mixture Design of Stone Matrix Asphalt
}

\author{
Yanping Sheng ${ }^{1, *}$, Haibin $\mathrm{Li}^{2}$, Ping Guo ${ }^{3}$, Guijuan Zhao ${ }^{2}$, Huaxin Chen ${ }^{1}$ and Rui Xiong ${ }^{1}$ \\ 1 School of Materials Science and Engineering, Chang'an University, Xi'an 710064, China; \\ chx92070@163.com (H.C.); xiongr61@126.com (R.X.) \\ 2 School of Architecture and Civil Engineering, Xi' an University of Science and Technology, Xi'an 710054, \\ China; lihaibin1212@126.com (H.L.); guijuanzhao@126.com (G.Z.) \\ 3 Xi' an Highway Research Institute, Xi'an 710054, Shaanxi, China; guoping8088@163.com \\ * Correspondence: syp@chd.edu.cn; Tel.:+86-1899-1848-117
}

\begin{abstract}
Lignin fibers typically influence the mixture performance of stone matrix asphalt (SMA), such as strength, stability, durability, noise level, rutting resistance, fatigue life, and water sensitivity. However, limited studies were conducted to analyze the influence of fibers on the percent voids in mineral aggregate in bituminous mixture (VMA) during the mixture design. This study analyzed the effect of different fibers and fiber contents on the VMA in SMA mixture design. A surface-dry condition method test and Marshall Stability test were applied on the SMA mixture with four different fibers (i.e., flocculent lignin fiber, mineral fiber, polyester fiber, blended fiber). The test results indicated that the bulk specific gravity of SMA mixtures and asphalt saturation decreased with the increasing fiber content, whilst the percent air voids in bituminous mixtures (VV), Marshall Stability and VMA increased. Mineral fiber had the most obvious impact on the bulk specific gravity of bituminous mixtures, while flocculent lignin fiber had a minimal impact. The mixture with mineral fiber and polyester fiber had significant effects on the volumetric properties, and, consequently, exhibited better VMA over the conventional SMA mixture with lignin fiber. Modified fiber content range was also provided, which will widen the utilization of mineral fiber and polyester fiber in the applications of SMA mixtures. The mixture evaluation suggested no statistically significant difference between lignin fiber and polyester fiber on the stability. The mineral fiber required a much larger fiber content to improve the mixture performance than other fibers. Overall, the results can be a reference to guide SMA mixture design.
\end{abstract}

Keywords: stone matrix asphalt; volume parameters; Marshall Stability; flocculent lignin fiber; polyester fiber; mineral fiber; fiber content

\section{Introduction}

Stone matrix asphalt (SMA) is a hot asphalt mixture in which coarse aggregate interlocks to form a stone skeleton that resists permanent deformation. SMA was first used in Europe as a mixture that would resist the wear of studded tires. Then it was used successfully in the United States in 1990, and is now widely used in China. The advantages of SMA include high resistance to rutting, excellent low-temperature performance, improved macrotexture, long service life, low tire noise, less water spray from tires, and weak light reflection on rainy nights [1-3]. However, the coarse texture of an SMA mixture may result in more internal air voids that are related to performance degradation, even when the volume of air voids is the same as that of common asphalt mixtures [4]. The coarse surface texture makes it more difficult to differentiate between mixture air voids and surface texture.

Fiber additive is important for SMA due to its oil absorptive characteristics. A certain quantity of fiber should be added into the SMA mixture in order to prevent asphalt from flowing out due to the high asphalt content. The outflow of the asphalt can result in fat spots on the pavement surface [5]. The mineral skeleton of coarse aggregate supplies the mixture with a strong particle interlock 
increasing the mixture resistance, and the mastic supplies the mixture with better durability. Since the fiber occupies some space, the gap between aggregates will be increased if it blocks the contact of the aggregates, and then the mixture performance will be reduced through the influence of volumetric parameters. The volumetric parameters are the direct controlling indicators in the design and preparation of the SMA mixtures.

In the early stage of hot-mix-asphalt (HMA) mix design, percent voids in mineral aggregate in bituminous mixtures (VMA) were determined and maintained throughout the mix-design procedure. VMA includes the air voids and the volume occupied by the effective asphalt content. This volumetric property is correlated to mechanical properties [6-8], e.g., small percent air voids in bituminous mixtures (VV) will cause bleeding and high VV may lead to water damage or instability in asphalt pavement. In addition to the size gradation, VMA is one of the most important HMA design criteria to obtain durable pavement, and it significantly affects the permanent deformation and fatigue performance of a compacted mix $[9,10]$. The use of VMA criteria for mix design is a time-honored and fairly successful tool. The VMA requirements for HMA mixtures were initially developed in the 1950s and were considered one of the most important volumetric parameters for HMA and SMA mixtures [11,12]. Then other influence factors of VMA, such as aggregate factors and volumetric basis, were pointed out, and VMA specifications were strongly emphasized during the process of asphalt mixture design and analysis [12-15].

In order to determine VMA, the bulk density, percent air voids in bituminous mixtures (VV), and percent voids in mineral aggregate that are filled with asphalt in bituminous mixtures (VFA) have to be obtained first because they are critical parameters to obtain proper VMA in design and practice. Studies have reported the difficulty of meeting the minimum VMA requirement in an efficient manner $[10,16,17]$. It indicated that the minimum VMA should be based on the minimum asphalt film thickness rather than the minimum asphalt content [18]. Although both Bailey's method and the NCHRP 9-33 manual have provided suggestions for adjusting the mix design to achieve the target VMA, the determination of VMA still requires a large amount of experimental testing [15,19]. As another point of view, VMA was to incorporate at least the minimum permissible asphalt content into the mixture to ensure its durability. VMA and the shape of aggregate particles influence workability, shear resistance, fatigue, and durability of the mixture [20-24].

The most commonly adopted fibers in SMA mixtures are lignin fibers. The success in SMA mixtures spurred the adoption of the fiber for many major highway projects. Then, lignin fiber, glass fiber, and mineral fiber have been studied in asphalt mixtures [25,26]. From then on, other types of fibers, such as carpet fiber, polyester fiber, waste tires, cellulose oil palm fiber, waste glass fiber, and coconut fiber, were used to study the service properties of the HMA mixture and SMA mixture [2630]. The studies focused on the mixture to obtain a better performance, such as strength, stability, durability, reduction of noise, rutting resistance, fatigue life, and water sensitivity. However, fiber types may influence oil absorption and fiber content will affect the VV. Then it can affect the VMA directly. Limited studies were conducted to analyze the influence of fibers on the VMA during the mixture design.

Therefore, this study investigated the effects of four different fibers on the mixture volume parameter during the SMA mixture design, with the goal of identifying the adaptability of polyester fiber and mineral fiber for satisfactory binder performance. The mineral fiber has a similar density with aggregates and smaller oil absorption and specific surface area, which means it cannot absorb much asphalt binder to fill the mineral outside space, and is less sensitive to the content change. Polyester fiber has better asphalt absorption and higher ductility; therefore, it can form much more space in the SMA mixture [31]. High content of polyester fiber means low asphalt content, which potentially reduces the adhesion between the aggregate and asphalt binder.

Empirical binder tests were conducted to identify volume parameters and appropriate contents of different fibers. The bulk specific gravity of bituminous mixtures, VV, VFA, and VMA, were studied with a surface-dry condition method test. Then, the Marshall Stability of the SMA mixtures with optimized mixing procedures was evaluated to check the effect of the fibers on the mechanical performance. The flocculent lignin fiber was used as a control fiber. The suggested fiber content of 
this study for different fibers could provide better performance of the SMA mixture. The results provide effective references for the SMA mixture design.

\section{Materials and Methods}

\subsection{Materials}

\subsubsection{Asphalt Binder}

A modified asphalt binder, i.e., styrene-butadiene-styrene (SBS) (I-C), which has been regularly used in pavement engineering, was selected in this study. Table 1 shows the measured technical indicators of the SBS asphalt binder. Basic binder tests, such as the penetration, softening point, and ductility were conducted to evaluate the fundamental characteristics of SBS asphalt binder which may influence the SMA mixture.

The asphalt penetration test is used to evaluate the asphalt's soft and hard levels and its shear resistance. The test reflects the asphalt's relative viscosity. The softening point test is used to determine the temperature at which the asphalt becomes soft and achieves a certain viscosity. Ductility is mainly about deformability of asphalt and indirectly reflects low-temperature anti-cracking property. It is an important index that can be used to evaluate asphalt plasticity such that the larger the ductility value, the better plasticity of the asphalt. All of these are part of the basic performance index to evaluate the asphalt binder.

Table 1. Technical indicators of the asphalt binder.

\begin{tabular}{|c|c|c|c|c|}
\hline \multicolumn{2}{|c|}{ Test Properties } & Unit & Test Results & $\begin{array}{r}\text { Specification } \\
\text { Requirements }\end{array}$ \\
\hline \multicolumn{2}{|c|}{ Penetration $\left(25^{\circ} \mathrm{C}, 100 \mathrm{~g}, 5 \mathrm{~s}\right)$} & $0.1 \mathrm{~mm}$ & 71.7 & $60 \sim 80$ \\
\hline \multicolumn{2}{|c|}{ Softening point } & ${ }^{\circ} \mathrm{C}$ & 97 & $\geq 55$ \\
\hline \multicolumn{2}{|c|}{ Ductility $\left(5^{\circ} \mathrm{C}, 5 \mathrm{~cm} / \mathrm{min}\right)$} & $\mathrm{cm}$ & 33.4 & $\geq 30$ \\
\hline \multicolumn{2}{|c|}{ Penetration index } & - & 0.21 & $\geq-0.4$ \\
\hline \multicolumn{2}{|c|}{ Density $\left(15^{\circ} \mathrm{C}, \mathrm{g} / \mathrm{cm}^{3}\right)$} & - & 1.032 & - \\
\hline \multicolumn{2}{|c|}{ Viscosity $\left(135^{\circ} \mathrm{C}\right)$} & $\mathrm{Pa} \cdot \mathrm{s}$ & 1.83 & $\leq 3$ \\
\hline \multicolumn{2}{|c|}{ Flash point } & ${ }^{\circ} \mathrm{C}$ & 328 & $\geq 230$ \\
\hline \multirow{3}{*}{\multicolumn{2}{|c|}{$\begin{array}{c}\text { Solubility (Trichloroethylene) } \\
\text { Segregation, } 48 \mathrm{~h} \text { D-value of Softening point } \\
\text { Elastic recovery }\left(25^{\circ} \mathrm{C}\right)\end{array}$}} & $\%$ & 99.37 & $\geq 99$ \\
\hline & & ${ }^{\circ} \mathrm{C}$ & 2.1 & $\leq 2.5$ \\
\hline & & $\%$ & 98 & $\geq 65$ \\
\hline \multirow{3}{*}{$\begin{array}{l}\text { Short-term oven aging, } \\
163^{\circ} \mathrm{C}, 75 \mathrm{~min}\end{array}$} & Mass change & $\%$ & 0.006 & $\leq \pm 1.0$ \\
\hline & $\begin{array}{l}\text { Penetration ratio, } \\
25^{\circ} \mathrm{C}\end{array}$ & $\%$ & 76.4 & $\geq 60$ \\
\hline & Ductility, $5^{\circ} \mathrm{C}$ & $\mathrm{cm}$ & 29.3 & $\geq 20$ \\
\hline
\end{tabular}

\subsubsection{Aggregate}

The diabase gravel and the limestone sand were chosen as coarse aggregate and fine aggregate in this study. Some important technical indicators are listed in Tables 2 and 3, respectively. To create a better adhesion between the aggregate and the asphalt binder during the mixing procedure, the aggregates were first cleaned and then dried well. The required amounts of aggregates and fillers were placed into an oven at $105^{\circ} \mathrm{C}$ for $5 \mathrm{~h}$, and then the temperature rose to $180^{\circ} \mathrm{C}$ for mixing. 
Table 2. Technical indicators of coarse aggregate.

\begin{tabular}{|c|c|c|c|c|}
\hline \multicolumn{2}{|l|}{ Test Properties } & Unit & Test Results & $\begin{array}{c}\text { Specification } \\
\text { Requirements }\end{array}$ \\
\hline \multicolumn{2}{|c|}{ Apparent relative density } & - & 2.927 & $\geq 2.60$ \\
\hline \multicolumn{2}{|l|}{ Crushing value } & $\%$ & 8.3 & $\leq 26$ \\
\hline \multicolumn{2}{|l|}{ Sturdiness } & $\%$ & 9.8 & $\leq 12$ \\
\hline \multicolumn{2}{|c|}{ LA abrasion value } & $\%$ & 10.2 & $\leq 28$ \\
\hline \multicolumn{2}{|c|}{ Water absorption } & $\%$ & 0.48 & $\leq 2.0$ \\
\hline \multicolumn{2}{|c|}{ Adhesion with asphalt } & Grade & 5 & 5 \\
\hline \multicolumn{2}{|c|}{$<0.075 \mathrm{~mm}$ Grain content } & $\%$ & 0.3 & $\leq 1$ \\
\hline \multicolumn{2}{|l|}{ Soft stone content } & $\%$ & 1.1 & $\leq 3$ \\
\hline \multirow{3}{*}{$\begin{array}{l}\text { Needle and plate particle } \\
\text { content }\end{array}$} & Mixture & $\%$ & 6.2 & $\leq 15$ \\
\hline & $>9.5 \mathrm{~mm}$ & $\%$ & 5.3 & $\leq 12$ \\
\hline & $<9.5 \mathrm{~mm}$ & $\%$ & 9.3 & $\leq 18$ \\
\hline
\end{tabular}

Table 3. Technical indicators of fine aggregate.

\begin{tabular}{cccc}
\hline Test Properties & Unit & Test Results & Specification Requirements \\
\hline Sturdiness $(>0.3 \mathrm{~mm})$ & $\%$ & 14 & $\geq 12$ \\
Apparent relative density & - & 2.745 & $\geq 2.50$ \\
Methylene blue value $(\mathrm{g} / \mathrm{Kg})$ & $\%$ & 10.6 & $\leq 25$ \\
Angularity (flow time) & $\mathrm{s}$ & 43.1 & $\geq 30$ \\
\hline
\end{tabular}

\subsubsection{Mineral Filler}

The mineral filler was produced by limestone. Some important technical indicators of mineral filler were shown in Table 4.

Table 4. Technical indicators of mineral filler.

\begin{tabular}{cccc}
\hline Test Properties & Unit & Test Results & Specification Requirements \\
\hline Apparent density & $\mathrm{t} / \mathrm{m}^{3}$ & 2.726 & $\geq 2.50$ \\
Hydrophilic coefficient & - & 0.7 & $<1$ \\
Plasticity index & $\%$ & 2.3 & $<4$ \\
Water content & $\%$ & - & $\leq 1.0$ \\
\hline
\end{tabular}

\subsubsection{Fiber}

Four different fibers, i.e., flocculent lignin fiber, mineral fiber, polyester fiber, and blended fiber, were selected in order to analyze the effect on VMA at different fiber contents. The blended fiber was made up of flocculent lignin fiber and polyester fiber with mass ratio of 2:1. Some important technical indicators of these fibers are listed in Table 5.

Table 5. Technical indicators of different fibers.

\begin{tabular}{ccccc}
\hline Test Properties & Unit & $\begin{array}{c}\text { Flocculent } \\
\text { Lignin Fiber }\end{array}$ & $\begin{array}{c}\text { Polyester } \\
\text { Fiber }\end{array}$ & $\begin{array}{c}\text { Mineral } \\
\text { Fiber }\end{array}$ \\
\hline Relative density & $\mathrm{g} / \mathrm{cm}^{3}$ & 1.813 & 1.390 & 2.720 \\
Length & $\mathrm{mm}$ & 5 & 6 & 4 \\
Thickness & $\mathrm{mm}$ & 0.047 & - & - \\
Diameter & $\mu \mathrm{m}$ & - & - & 5 \\
Ash content (by weight) & $\%$ & 16 & - & - \\
PH value & - & 6.9 & 2.43 & - \\
Water content rate (by weight) & $\%$ & 3 & 4.1 & - \\
Oil absorption rate & times & 6.5 & & \\
\hline
\end{tabular}




\begin{tabular}{ccccc} 
Melting points & ${ }^{\circ} \mathrm{C}$ & - & 260 & $>1000$ \\
Tensile strength & $\mathrm{MPa}$ & - & 570 & 935 \\
\hline
\end{tabular}

\subsection{Test Methods}

\subsubsection{Mixing Proportion Determination}

A typical SMA mixture, i.e., SMA-13 with a nominal maximum aggregate size of $13.2 \mathrm{~mm}$, which has been regularly used in asphalt pavement construction, was selected to study volumetric parameters and mixture stability. Table 6 and Figure 1 show the gradation of the SMA-13. As an additive, the fiber was added to make mixture specimens.

Table 6. Gradation of SMA-13 asphalt mixture.

\begin{tabular}{cccccccccccc}
\hline \multirow{2}{*}{ Composite } & \multirow{2}{*}{ Percentage } & \multicolumn{10}{c}{ Mesh Size $(\mathbf{m m} / \mathbf{\%})$} \\
\cline { 3 - 12 } & & $\mathbf{1 6 . 0}$ & $\mathbf{1 3 . 2}$ & $\mathbf{9 . 5}$ & $\mathbf{4 . 7 5}$ & $\mathbf{2 . 3 6}$ & $\mathbf{1 . 1 8}$ & $\mathbf{0 . 6}$ & $\mathbf{0 . 3}$ & $\mathbf{0 . 1 5}$ & $\mathbf{0 . 0 7 5}$ \\
\hline $9.5 \sim 16 \mathrm{~mm}$ & $44 \%$ & 100 & 85.1 & 12.3 & 0.40 & 0.40 & 0.40 & 0.40 & 0.40 & 0.40 & 0.40 \\
$4.75 \sim 9.5 \mathrm{~mm}$ & $33 \%$ & 100 & 100 & 97.9 & 8.6 & 0.5 & 0.50 & 0.50 & 0.50 & 0.50 & 0.50 \\
$0 \sim 2.36 \mathrm{~mm}$ & $13 \%$ & 100 & 100 & 100 & 100 & 92.6 & 62.0 & 36.1 & 19.9 & 13.6 & 9.9 \\
Mineral filler & $10 \%$ & 100 & 100 & 100 & 100 & 100 & 100 & 100 & 99.3 & 95.4 & 85.3 \\
\hline
\end{tabular}

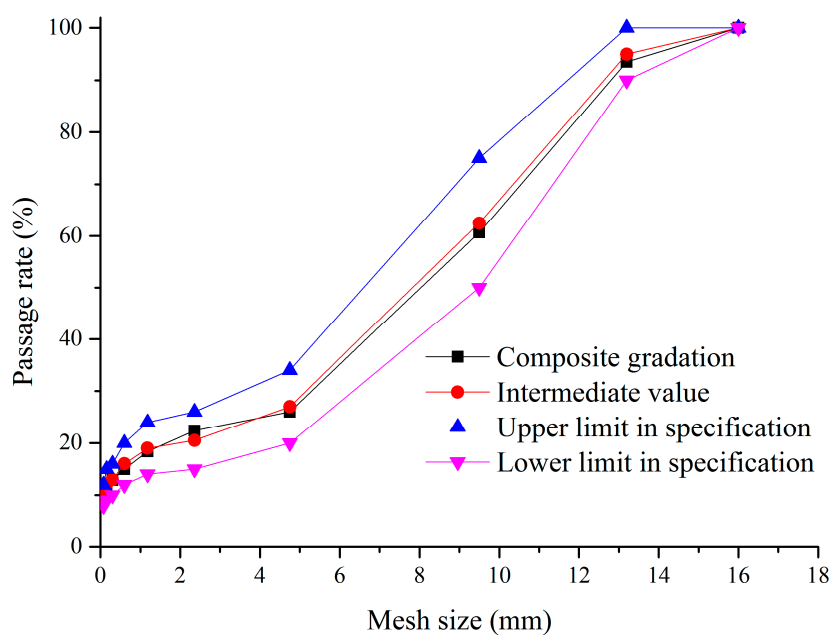

Figure 1. Gradation of the SMA-13 mixture.

Using the materials and the aggregate gradation described above, the SMA mixtures with different fibers and $0.3 \%$ content (by the weight of total mix) was prepared for laboratory testing. The optimal asphalt aggregate ratio of SMA mixtures with different fibers shown in Table 7 were determined according to the Marshall mixture design method of the Chinese technical specification for construction of highway asphalt pavements (JTG F40-2004).

Table 7. Asphalt aggregate ratio of SMA mixtures with different fibers.

\begin{tabular}{ccccc}
\hline Different Fibers & $\begin{array}{c}\text { Flocculent Lignin } \\
\text { Fiber }\end{array}$ & $\begin{array}{c}\text { Mineral } \\
\text { Fiber }\end{array}$ & $\begin{array}{c}\text { Polyester } \\
\text { Fiber }\end{array}$ & $\begin{array}{c}\text { Blended } \\
\text { Fiber }\end{array}$ \\
\hline Asphalt aggregate ratio (\%) & 5.9 & 5.5 & 5.7 & 5.9 \\
\hline
\end{tabular}

\subsubsection{SMA Sample Preparation}

In this study, SMA specimens were prepared using the compaction method. The dimensions were $101.6 \mathrm{~mm} \times 63.5 \mathrm{~mm}$. According to the standard requirement and field construction experience, the fiber content (by the weight of the total mix) used in the SMA mixture was selected, which was 
$0.1 \%, 0.2 \%, 0.3 \%, 0.4 \%, 0.5 \%$, and $0.6 \%$, respectively. The fiber types and contents are shown in Table 8 .

Table 8. Different fiber types and fiber content in SMA mixtures.

\begin{tabular}{|c|c|c|c|c|c|c|c|c|c|c|c|}
\hline \multirow{2}{*}{$\begin{array}{c}\text { Type } \\
\text { Content (\%) }\end{array}$} & \multicolumn{5}{|c|}{ Flocculent Lignin Fiber } & \multicolumn{6}{|c|}{ Mineral Fiber } \\
\hline & 0.1 & 0.2 & 0.3 & 0.4 & 0.5 & 0.1 & 0.2 & 0.3 & 0.4 & 0.5 & 0.6 \\
\hline Type & \multicolumn{5}{|c|}{ Blended fiber } & \multicolumn{6}{|c|}{ Polyester fiber } \\
\hline Content (\%) & 0.1 & 0.2 & 0.3 & 0.4 & 0.5 & 0.1 & 0.2 & 0.3 & 0.4 & 0.5 & - \\
\hline
\end{tabular}

The density was determined with the surface-dry condition method (T0705-2011/JTG E20-2011), which was very similar to ASTM D2726-14. There were mainly two differences. First, ASTM D2726-14 explained if the temperature of the specimen differs from the temperature of the water bath by more than $2{ }^{\circ} \mathrm{C}\left(3.6^{\circ} \mathrm{F}\right)$, the specimen should be immersed in the water bath for 10 to $15 \mathrm{~min}$; instead of 3 to $5 \mathrm{~min}$. The immersed time in the water bath was only 3 to $5 \mathrm{~min}$ in the T0705-2011. Secondly, ASTM D2726-14 required, after determining the mass in water and in a saturated-surface dry condition, thoroughly drying the specimen to a constant mass at $110 \pm 5^{\circ} \mathrm{C}\left(230 \pm 9^{\circ} \mathrm{F}\right)$. While it only required making the specimens thoroughly dry, it did not illustrate the temperature in the T0705-2011.

The loose fibers (by the weight of total mix) were first blended with the hot aggregates to prevent the asphalt binder from draining during the mixing procedure. The heated asphalt binder was added after mixing 1 to $1.5 \mathrm{~min}$. Then the heated filler was added until all of the aggregate was completely covered. The total mixing time was $3 \mathrm{~min}$. During the mixing process, the temperature was kept between $170^{\circ} \mathrm{C}$ and $180^{\circ} \mathrm{C}$. Finally, the Marshall specimens were made with dimensions of $101.6 \mathrm{~mm} \times 63.5 \mathrm{~mm}$ using the compaction method. For note, the final temperature was greater than $145^{\circ} \mathrm{C}$.

\subsubsection{Marshall Stability and Flow Tests}

The Marshall stability and flow tests were conducted to evaluate the resistance of asphalt mixtures to distortion, displacement, rutting, and shearing stresses. The stability test measures the maximum load sustained by the specimen at a loading rate of $50.8 \mathrm{~mm} / \mathrm{min}$. Basically, the applied testing load increases until the specimen splits into two pieces, then the loading is finished and the maximum load is recorded as the Marshall Stability.

\section{Results and Discussion}

\subsection{Effect of Fiber on Bulk Specific Gravity, VV, and VFA}

Figure 2 displayed the bulk specific gravity of SMA mixtures with different fibers and fiber contents. The data show an inverse correlation between bulk specific gravity of SMA mixtures and fiber content for fiber types. The SMA mixture with mineral fiber had the largest bulk specific gravity values, followed by the mixture with polyester fiber. The mixture with flocculent lignin fiber had the smallest values. All of the bulk specific gravity values were between 2.465 and 2.523. The bulk specific gravity of SMA mixtures with polyester fiber and blended fiber decreased with fiber content increasing from $0.1 \%$ to $0.4 \%$, and then it maintained a slight decrease with fiber content from $0.4 \%$ to $0.5 \%$. The mixture with mineral fiber had a similar variety, with the only difference being the relatively smaller reduction in fiber content from $0.5 \%$ to $0.6 \%$.

These results indicated that it was not necessarily true that the larger bulk specific gravity of the SMA mixture results from a higher fiber content. The higher fiber content results in lower bulk specific gravity. In terms of the four different fibers, the mineral fiber has a density very close to that of the aggregate, and it was much easier to combine with the asphalt binder than other fibers. Under the same compaction effort, the SMA mixture with mineral fiber can reach a larger dry mass per unit volume. Therefore, it appeared to have a larger bulk specific gravity value. 


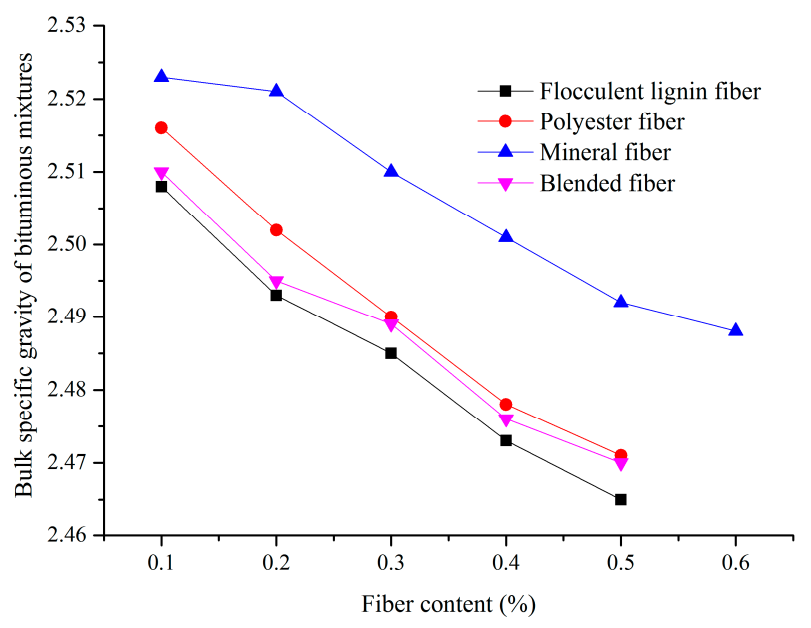

Figure 2. Bulk specific gravity of SMA mixtures with four different fibers.

Figure 3 displayed the percent air voids in SMA mixtures with different fibers and fiber contents. The data showed a positive correlation between VV and fiber content. Higher fiber content resulted in better asphalt absorption and adsorption in the SMA mixture. The measured VV values of different fiber types and contents were between $2.9 \%$ to $4.4 \%$.

It was found from the results that the polyester fiber had an important impact on the VV values when the content was up to $0.2 \%$. It indicated that polyester fiber prevented the aggregates contacting each other and formed much more space in the mixture due to its higher ductility. The VV with polyester fiber, flocculent lignin fiber, and blended fiber increased with the fiber content increasing from $0.1 \%$ to $0.4 \%$, and then it maintained a slight increase with the fiber content from $0.4 \%$ to $0.5 \%$, and the increments of flocculent lignin fiber, polyester fiber, and blended fiber were $4.5 \%, 1.9 \%$, and $4.9 \%$, respectively. However, mineral fiber had little impact on VV values when the content was less than $0.2 \%$ due to the negligible impact on the asphalt absorption. However, when the content was more than $0.2 \%$, mineral fiber began to show its effect on absorptive action and the mixture's adsorption, for which the VV showed a significant increase. At the same content, the mixture with polyester fiber had the largest $\mathrm{VV}$ value.

In practice, the optimum fiber type and content should be selected to achieve satisfactory performance of the SMA mixture in the production process. This study suggests that the minimum content is above $0.3 \%$ for mineral fiber and above $0.2 \%$ for the other fibers. However, the specific value may depend more on other factors, such as cost considerations, availability, and ease of field construction application because of the difference between lab tests and field construction.

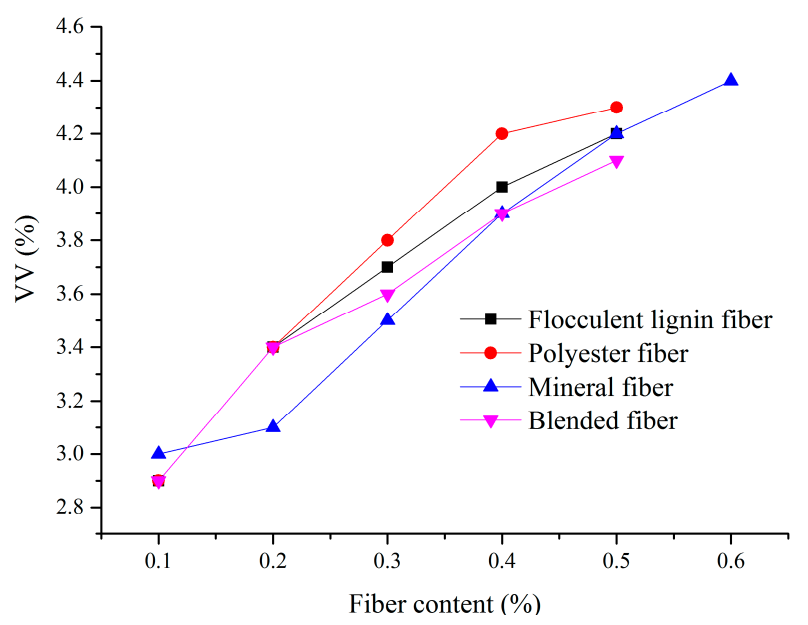

Figure 3. Percent air voids in SMA mixtures with four different fiber types. 
Figure 4 showed the percentage of voids in mineral aggregate (VFA) that are filled with asphalt in SMA mixtures with different fibers and fiber contents. The data from Figure 4 indicated that fiber types and contents had an obvious impact on VFA, which decreased as fiber content increased. All of the VFA values were between $73 \%$ and $82 \%$. The percentage of voids in mineral aggregate that are filled with asphalt in SMA mixtures with blended fiber, flocculent lignin fiber, and polyester fiber decreased with the fiber content increasing from $0.1 \%$ to $0.4 \%$, and then it maintained a slight decrease with fiber content from $0.4 \%$ to $0.5 \%$. When the additive was mineral fiber, it had similar variety, with the only difference being the relatively smaller reduction in the content from $0.1 \%$ to $0.2 \%$ and $0.5 \%$ to $0.6 \%$.

The content change of mineral fiber had a negligible impact on the VFA values due to its large density and low oil absorption rate when the content was less than $0.2 \%$. Then VFA showed a significant decrease after the content was more than $0.2 \%$. However, when the mineral fiber content was up to $0.4 \%$, it began to show its absorptive action and the mixture's adsorption, which made the VFA much smaller than that with polyester fiber. The three other fibers had obvious impacts on the VFA value, and the SMA mixture with polyester fiber had a much smaller VFA than that with blended fiber and flocculent lignin fiber.

The results indicated that the mineral fiber and polyester fiber had better asphalt absorption and adsorption in the SMA mixture. To obtain the same VFA value, lower content is needed for mineral fiber and polyester fiber. Therefore, the fiber selection should comprehensively consider both absorptive action and the mixture's adsorption. Higher contents of mineral fiber and polyester fiber were not the best choice. Fiber with higher adsorption, but lower absorption, will improve the SMA mixture volume index.

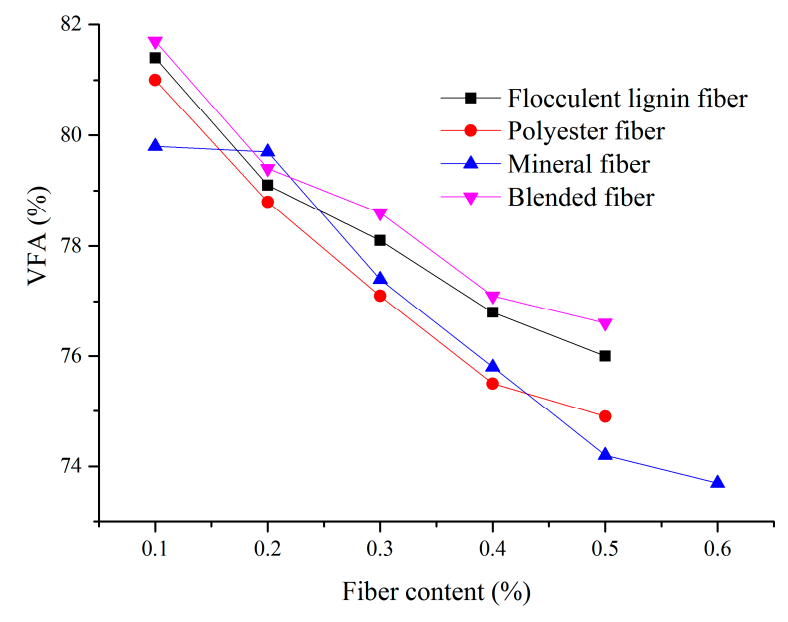

Figure 4. VFA of SMA specimens with four different fiber types.

\subsection{Effect of Fiber on Percent Voids in Mineral Aggregate in Bituminous Mixtures (VMA)}

Figure 5 displayed the percent voids in mineral aggregate in SMA mixtures. The VMA increased with fiber content increasing. The measured VMA values were between $15 \%$ and $18 \%$. At the same fiber content, the VMA value had the minimum gap between lignin fiber and blended fiber. It was only $16.4 \%$ even when the mineral fiber content was up to $0.5 \%$. The values were more than $17.3 \%$ for the other fibers. This indicated that the mineral fiber had the minimum impact on VMA. The same trend was found for Marshall Stability. Compared with the previous literature, the mix designer was able to judge the proper VMA requirement for each kind of fiber.

The VMA with polyester fiber, flocculent lignin fiber and blended fiber increased with fiber content increasing from $0.1 \%$ to $0.4 \%$, and then the increment gradually reduced with fiber content from $0.4 \%$ to $0.5 \%$. However, the content change of mineral fiber had a negligible impact on VMA when the content was less than $0.2 \%$. The mixture with mineral fiber had a similar variety with the only difference being the relatively lower VMA values with fiber contents from $0.2 \%$ to $0.6 \%$. When the content of flocculent lignin fiber, blend fiber, and polyester fiber was $0.3 \%$, and mineral fiber 
content was $0.4 \%$, the VMA values of SMA mixtures were $16.7 \%, 16.7 \%, 16.5 \%$, and $16.1 \%$, respectively, which explained much more mineral fiber content was needed to achieve a target VMA value in the SMA mixture design.

Furthermore, mineral fiber had a similar density with aggregate and smaller oil absorption and smaller specific surface area; it cannot absorb much asphalt binder to fill the outside space of the mineral fiber. Therefore, effective asphalt content was not sensitive to the content change. Therefore, the SMA mixture with mineral fiber can obtain a lower VMA under the same compaction effort. These test findings can be a reference and used to promote the use of fibers in SMA mixtures.

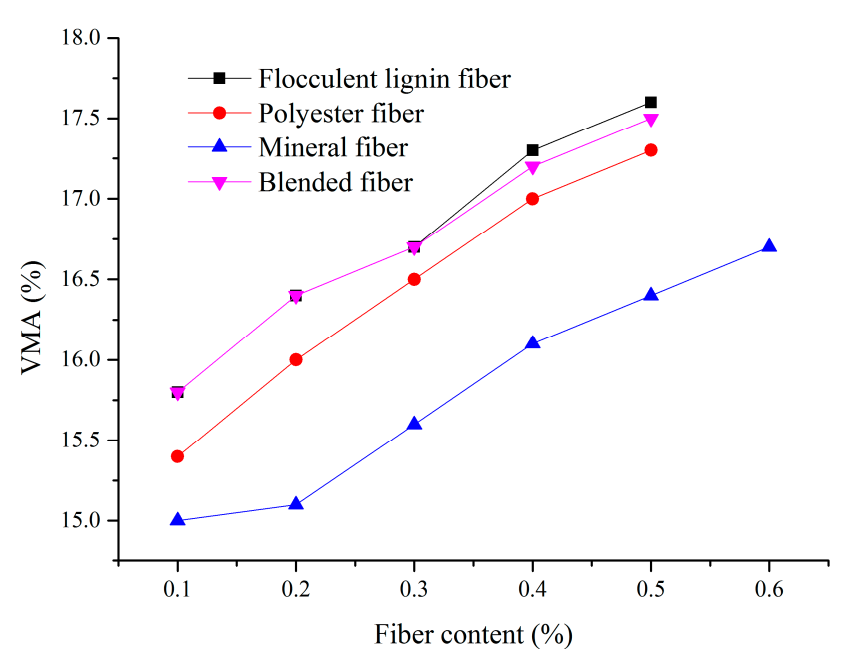

Figure 5. VMA of SMA specimens with four different fiber types.

\subsection{Effect of Fiber on Marshall Stability}

Figure 6 displayed the Marshall Stability of SMA mixtures. It had the similar trend with VV. All of the Marshall Stability values were between 7 and $14 \mathrm{kN}$. Compared with the previous literature, this was larger than with cellulose oil palm fibers. The data from Figure 6 indicated that fiber types and contents had evident correlations between fiber content and Marshall Stability, which increased with fiber content increasing. When the fiber content was less than $0.3 \%$, the SMA mixture with polyester fiber showed better stability. When the fiber content was larger than $0.3 \%$, the SMA mixture with blended fiber showed better stability than that with the other three fibers.

The SMA mixture with the mineral fiber had the lowest Marshall Stability values within the content ranges. The amount of polyester fiber was the smallest at the same Marshall Stability when the fiber content was larger than $0.2 \%$, followed by blended fiber, flocculent lignin fiber, and mineral fiber. Meanwhile, the Marshall Stability of SMA mixtures with polyester fiber and flocculent lignin fiber increased with the fiber content increasing from $0.1 \%$ to $0.3 \%$. The Marshall Stability then maintained a slight increase with the fiber content from $0.3 \%$ to $0.5 \%$, and $0.4 \%$ to $0.6 \%$ for the blended fiber and the mineral fiber. 


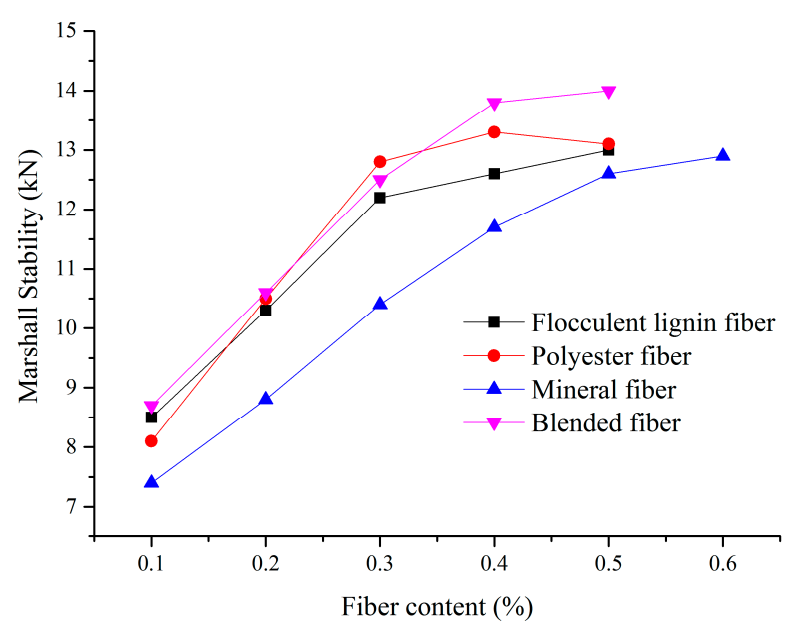

Figure 6. Marshall Stability of the SMA mixtures with four different fibers.

\section{Conclusions}

HMA and SMA are commonly used pavement materials which are composed of aggregates, fillers, binders, and fibers. These loose materials are mixed together by controlling the volumetric properties to obtain an optimum mechanical performance. Thus, the volumetric properties are the direct indicators in design and construction practice. This paper analyzed the effects of four fibers on the volumetric parameters and Marshall Stability (mechanical performance) of SMA mixtures. As a control fiber, the flocculent lignin fiber was compared with the other three fibers.

This paper found that both the polyester fiber and mineral fiber had an obvious impact on VV, VFA, VMA, and Marshall Stability of the SMA mixture compared to the regular flocculent lignin fiber. The experiment data indicated that increasing the content of polyester fiber and mineral fiber benefitted the mechanical performance of SMA mixtures, which potentially enlarged the fibers' application range. This study suggests that the optimum fiber content is to be larger than $0.3 \%$ for flocculent lignin fiber, blended fiber, and polyester fiber, and larger than $0.4 \%$ for mineral fiber.

When fiber content was up to $0.5 \%$, the VMA of the sample with the mineral fiber and the polyester fiber was both larger than $16.4 \%$. However, it was more than $17.5 \%$ for lignin fiber and blended fiber. Therefore, SMA mixtures with mineral fiber and polyester fiber will be better in heavy traffic sections or hot areas with larger high-temperature stability. They can provide more options in SMA mixture design, which indicates the significant potential for their application. Fiber with higher adsorption, but lower absorption, is a better choice as a potential alternative for lignin fiber in SMA mixture design and construction.

The study proved the adaptability of polyester fiber and mineral fiber in SMA mixture design and provided proper content ranges of the fibers. However, other factors (e.g., cost, availability, and ease of field construction application) should be considered in practice. The fiber type and fiber content should be selected according to field construction experience. The results obtained from the lab tests are a reference to bring convenience to field projects.

In the future, microstructure analysis will be the research emphasis. The dispersion and dissolution of mineral fiber or polyester fiber in the asphalt binder will be characterized with micro-analytical instruments. Then, the chemical reactions between polyester fiber and the asphalt binder can be evaluated. Finally, the high-temperature stability and cracking performance (load-induced, fatigue, top-down, etc.,) of SMA mixtures with mineral fiber and polyester fiber will be evaluated in different areas. Through synthetic consideration of microscopic analysis and field construction, the application range of mineral fiber and polyester fiber will be further expanded in pavement industries and create economic benefits. 
Acknowledgments: The project was supported by the National Natural Science Foundation of China (No. 51608046), Qinghai Transportation Science and Technology Project (No. 2014-GX-A2A), the Special Fund for Basic Scientific Research of Central Colleges Chang'an University (No. 310831171009 and 310831171001 ) and China Postdoctoral Science Foundation (No. 2015T81000 and 2015M582590). Y. Sheng also appreciates the funding from the Chinese Scholarship Council (CSC) of the Ministry of Education, P.R. China.

Author Contributions: Yanping Sheng and Haibin Li conceived and designed the experiments; Ping Guo and Guijuan Zhao performed the experiments; Huaxin Chen and Rui Xiong analyzed the data; Yanping Sheng and Haibin Li wrote the paper.

Conflicts of Interest: The authors declare no conflict of interest.

\section{References}

1. Cooley, L.A., Jr.; Hurley, G.C. Potential of using stone matrix asphalt (SMA) in Mississippi. Available online:

http://mdot.ms.gov/documents/research/Reports/Interim\%20and\%20Final\%20Reports/Using\%20Stone\%2 0Matrix\%20Asphalt\%20(SMA)\%20In\%20Mississippi.pdf (accessed on 11 March 2017).

2. Dong, Y.; Tan, Y. Mix design and performance of crumb rubber modified asphalt SMA. J. Mater. Civil Eng. 2011, 10, 78-86.

3. Xue, Y.J.; Hou, H.B.; Zhu, S.J.; Zha, J. Utilization of municipal solid waste incineration ash in stone mastic asphalt mixture: Pavement performance and environmental impact. Constr. Build. Mater. 2009, 23, 989-996.

4. Xie, H.B.; Watson, D. Determining air voids content of compacted stone matrix asphalt mixtures. Transp. Res. Record: J. Transp. Res. Board 2014, doi:http://dx.doi.org/10.3141/1891-24.

5. Micheal, L.; Burke, G.; Schwartz, C.W. Performance of stone matrix asphalt pavements in Maryland. Asph. Paving Technol.: Assoc. Asph. Paving Technol. 2003, 72, 287-314.

6. Christensen, D.W.; Pellinen, T.; Bonaquist, R.F. Hirsch model for estimating the modulus of asphalt concrete. J. Assoc. Asph. Paving Technol. 2003, 72, 97-121.

7. You, Z.P.; Dai, Q.L. Dynamic complex modulus predictions of hot-mix asphalt using a micromechanical-based finite element model. Can. J. Civil Eng. 2007, 34, 1519-1528.

8. Goh, S.W.; You, Z.P.; Williams R.; Li, X.J. Preliminary dynamic modulus criteria of HMA for field rutting of asphalt pavements: Michigan's experience. J. Transp. Eng. 2011, 137, 37-45.

9. Harvey, J.; Eriksen, K.; Sousa, J.; Monismith, C. Effects of laboratory specimen preparation on aggregateasphalt structure, air-voids contents measurement, and repetitive simple shear test results. Transportation Res. Board 1994, 113-122.

10. Hinrichsen, J.; Heggen, J. Minimum VMA in HMA based on gradation and volumetric properties. In Proceedings of the 75th Transportation Research Board Annual Meeting, Washington, DC, USA, 7-11 January 1996; Volume 1545, pp. 75-79.

11. McLeod, N.W. Void Requirements for Dense-Graded Bituminous Paving Mixtures; American Society for Testing and Materials (ASTM): Philadelphia, PA, USA, 1959, doi:10.1520/STP47179S.

12. Roberts, F.L.; Kandhal, P.S.; Brown, E.R.; Lee, D.-Y.; Kennedy, T.W. Hot Mix-Asphalt Materials, Mixture Design, and Construction, 2nd ed.; NAPA Research and Education Foundation: Lanham, MD, USA, 1991.

13. Hislop, W.; Corree, B. A laboratory investigation into the effects of aggregate-related factors of critical VMA in asphalt paving mixtures. Available online: http://publications.iowa.gov/11672/1/tr415.pdf (accessed on 11 March 2017).

14. Sengoz, B.; Topal, A. Minimum voids in mineral aggregate in hot-mix asphalt based on asphalt film thickness. Build. Environ. 2007, 42, 3629-3632.

15. Christensen, D.W. Draft final report to the National Cooperative Highway Research Program (NCHRP) on Project NCHRP 9-33: A mix design manual for hot mix asphalt. Advanced Asphalt Technologies, Sterling, VA, USA, 2009. Available online: http://www.trb.org/Main/Blurbs/161248.aspx

16. Anderson, R.M.; Bahia, H.U. Evaluation and selection of aggregate gradations for asphalt mixtures using Superpave. Transportation Res. Rec.: Transportation Res. Board 1997, 1583, 91-97.

17. Mallick, R.B.; Buchanan, M.S.; Kandhal, P.S.; Bradbury, R.L.; McClay, W. Rational approach of specifying the voids in the mineral aggregate for dense-graded hot-mix asphalt. In Proceedings of the 79th Annual Meeting of the Transportation Research Board, Washington, DC, USA, 9th Jan 2000.

18. Kandhal, P.S.; Foo, K.; Mallick, R. Critical review of voids in mineral aggregate requirements in Superpave. Transportation Res. Rec.: Transportation Res. Board 1998, 1609, $28-35$. 
19. Vavrik, W.R.; Huber, G.; Pine, W.J.; Carpenter, S.H.; Bailey, R. Bailey method for gradation selection in hot-mix-asphalt mixture design. Transportation Research E-Circular, E-C044, Transportation Research Board, Washington, DC, USA, 2002. Available online: www.trb.org/publications/circulars/ec044.pdf

20. Asphalt Institute Superpave Mix Design Series No.2 (SP-2). Lexington, Kentucky, 1996. Available online: http://www.asphaltinstitute.org/superpave-documents

21. Coree, B.J.; Hislop, W.P. A laboratory investigation into the effect of aggregate related factors of critical VMA in asphalt paving mixture. J.Assoc. Asph. Paving Technologists 2001, 70, 70-131.

22. Hargett, E.R. Effect of size, surface texture, and shape of aggregate particles on the properties of bituminous mixtures. Highw. Res. Board Special Rep. 1970, 25-26.

23. Barksdale, R.D.; Kemp, M.A.; Sheffield, W.J.; Hubbard, J.L. Measurement of aggregate shape, surface area, and roughness. Transportation Res. Rec. 1991, 107-116.

24. Adhikari, S.; You, Z.P. Investigating the sensitivity of aggregate size within sand mastic by modeling the microstructure of an asphalt mixture. J. Mater. Civil Eng. 2011, 23, 580-586.

25. Brown, E.R.; Manglorkar, H. Evaluation of Laboratory Properties of SMA Mixtures; NCAT Rep. No. 93-5; Auburn Univ.: Auburn, AL, USA, 1993.

26. Hassan, J.H.; Israa, J.Y. The effect of using glass power filler on hot asphalt concrete mixture properties. J. Eng. Technol. 2010, 29, 44-57.

27. Fu, Z.; Dang, Y.N.; Guo, B.; Huang, Y. Laboratory investigation on the properties of asphalt mixtures modified with double-adding admixtures and sensitivity analysis. J. Traffic Transp. Eng. (Engl. Ed.) 2016, 3, 412-426.

28. Putman, B.J.; Amirkhanian, S.N. Utilization of waste fiber in stone matrix asphalt mixtures. Resour. Conserv. Recycl. 2004, 42, 265-274.

29. Muniandy, R.; Huat, B.B.K. Laboratory diameteral fatigue performance of stone matrix asphalt with cellulose oil palm fiber. Am. J. Appl. Sci. 2006, 3, 2005-2010.

30. Al-Hadidy, A.I.; Tan, Y.Q. Mechanistic analysis of ST and SBS-modified flexible pavements. Constr. Build. Mater. 2009, 23, 2941-2950.

31. Chen, H.X.; Xu, Q.W. Experimental study of fibers in stabilizing and reinforcing asphalt binder. Fuel 2010, 89, 1616-1622.

(C) 2017 by the authors. Licensee Preprints, Basel, Switzerland. This article is an open access article distributed under the terms and conditions of the Creative Commons by Attribution (CC-BY) license (http://creativecommons.org/licenses/by/4.0/). 